Revista Brasileira de Farmacognosia Brazilian Journal of Pharmacognosy 21(3): 420-426, May./Jun. 2011

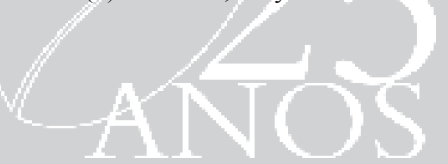

Article

Received 26 Mar 2010

Accepted 7 Nov 2010

Available online 1 Apr 2011

Keywords:

Satchytarpheta cayennensis

antioxidants

mitochondria

reactive oxygen species

fluorescent probes

ISSN 0102-695X

doi: $10.1590 / \mathrm{S} 0102-695 \mathrm{X} 2011005000050$

\section{Antioxidant activity of natural compounds of Stachytarpheta cayennensis by scavenger of mitochondrial reactive oxygen species}

\author{
Pierre André de Souza, ${ }^{*}$ Clara Rodrigues, ${ }^{2}$ Ana Paula S. A. \\ Santiago, ${ }^{3}$ Nanci Camara de Lucas, ${ }^{1}$ Gilda Guimaraes Leitao, ${ }^{4}$ \\ Antonio Galina Filho ${ }^{2}$
}

\begin{abstract}
${ }^{1}$ Instituto de Química, Departamento de Química Orgânica, Laboratório de Fotoquimica, Universidade Federal do Rio de Janeiro, Brazil,

${ }^{2}$ Instituto de Biofísica Carlos Chagas Filho, Programa de Biologia Celular e Parasitologia, Universidade Federal do Rio de Janeiro, Brazil,

${ }^{3}$ Instituto de Bioquímica Médica, Programa de Biofísica e Bioquímica Celular e Programa de Biologia Molecular e Biotecnologia, Universidade Federal do Rio de Janeiro, Brazil,

${ }^{4}$ Núcleo de Pesquisa de Produtos Naturais, Universidade Federal do Rio de Janeiro, Brazil.
\end{abstract}

\begin{abstract}
The etiology of a range of diseases is associated with an excessive generation of reactive oxygen species (ROS). Exacerbated ROS production leads to mitochondrial dysfunction, cellular damage and apoptosis. Nowadays, many strategies are being developed for the targeted delivery of antioxidants compounds to mitochondria, trying to minimize the damages. Production of ROS was investigated by the molecular probes $\mathrm{CM}-\mathrm{H}_{2}$ DCFDA and Amplex Red. The purpose of this work is to evaluate the antioxidant capacity of verbascoside, martinoside, betulinic acid from the Stachytarpheta cayennensis and quercetin by an in vitro assay with isolated mitochondria from mice's brain The results showed that all compounds tested exhibited a scavenger effect on the ROS generated by the isolated mitochondria, which displayed a dependent dose increase.
\end{abstract}

\section{Introduction}

Antioxidants react differently with the diverse free radicals and oxidant sources (Huang et al., 2005). During the last decade, natural antioxidant compounds from medicinal plants have aroused much attention, what resulted on increasing efforts to search for plantderived antioxidants against free radicals like reactive oxygen (ROS) and nitrogen species (RNS) (Huang et al., 2005; Pulido et al., 2005; Roginsky et al., 1996). Mitochondrial electron transport system (ETS) is considered to be one of the major sources of cellular ROS. The formation of ROS is inevitable during normal oxidative metabolism, and it is well established that some of the oxygen $\left(\mathrm{O}_{2}\right)$ consumed by the ETS generate ROS, mostly at complexes I and III (Cadenas et al., 1977, Cadenas \& Davies, 2000; Chen et al., 2003; Boveris et al., 1976; Boveris \& Chance, 1973; Turrens \& Boveris, 1980). The partial reduction of molecular oxygen, during oxidative phosphorylation, leads to a constant flux of superoxide anion $\left(\mathrm{O}_{2}^{-}\right)$, the precursor of hydrogen peroxide $\left(\mathrm{H}_{2} \mathrm{O}_{2}\right)$ radicals (Liu, 2002; Oliveira \& Kowaltowski, 2004). It has been described in the literature that in pathological conditions ROS production can be exacerbated, resulting in an imbalance between ROS generation and the intracellular levels of antioxidant defenses (Brand et al., 2004; Turrens 2003). It is involved in the pathology of many neurodegenerative diseases like Parkinson's disease, Alzheimer's disease, Huntington's disease, epilepsy and atherosclerosis (Freitas et al., 2005; Schapira, 2006). Others studies showed important role of antioxidant drugs such as ascorbic acid and $\alpha$-tocopherol can be used as scavengers of free radicals, reducing mice's brain injury (Tomé et al., 2010a; 2010b; Xavier et al., 2007).

Stachytarpheta cayennensis (Rich.) Vahl, Verbenaceae, is a Brazilian medicinal plant, commonly known as "gervao-roxo", "verbena" and "gerbao". The roots of this plant are used in Brazilian folk medicine for purulent ulcers and to treat sore skin wounds by topical application (De Souza., 2004; 
Penido et al., 2006; Schapoval et al., 1998). The most frequent ethnomedical usages of roots and leaves of S. cayennensis are as inflammations, ulcers, fever and diuretics (Penido et al., 2006; Schapoval et al., 1998). The anti-inflammatory activity of $S$. cayennensis has been demonstrated in rats by and Penido et al. (2006).

The aim of this study was to demonstrate the antioxidant properties of verbascoside, martinoside and betulinic acid compounds isolated from the roots of $S$. cayennensis. The antioxidant capacity was evaluated by an in vitro assay using mitochondria isolated from mice's brains like ROS source. For that, we used two fluorescent probes, Amplex Red and CM- $\mathrm{H}_{2} \mathrm{DCFDA}$, that are highly sensitive and stables markers for mitochondrial generated ROS with selectivity to $\mathrm{H}_{2} \mathrm{O}_{2}$ and free radicals, respectively (Valeur, 2001; Votyakova \& Reynolds, 2004; Zhou et al., 1997).

\section{Materials and Methods}

\section{Collection and extraction of plant material}

Roots of Stachytarpheta cayennesis (Rich.) Vahl, Verbenaceae, were collected at Conceição lake, Florianópolis, Santa Catarina, Brazil. Botanical identification was done by Inês M. Oliveira da Silva from the Department of Botany at Universidade Federal Rural do Rio de Janeiro, Brazil, where a voucher specimen is deposited (RBR 5979). The airdried and powdered roots $(367.8 \mathrm{~g})$ were placed in a Soxhlet apparatus and exhaustively extracted with $n$-hexane followed by ethanol, yielding $5.0 \mathrm{~g}$ and 48.0 $\mathrm{g}$ of crude hexane and ethanol extracts, respectively. The dried ethanol extract was suspended in $\mathrm{MeOH} /$ $\mathrm{H}_{2} \mathrm{O} 3: 2$ and extracted with hexane, chloroform, ethyl acetate and butanol, in this order. High-speed countercurrent chromatography (HSCCC) was applied to the preparative separation of the compounds verbascoside (2) (300.0 mg) and martinoside (3) (54.0 mg) from the ethyl acetate fraction and is described elsewhere (Leitao et al., 2005). Betulinic acid (4) (45.0 mg) was obtained from the chloroform fraction from the ethanol extract by HSCCC.

Selection of two-phase solvent system by the tube partitioning test

A small quantity of the chloroform fraction from the ethanol extract of the roots of S. cayennensis was dissolved in a series of test tubes containing the solvent systems $\mathrm{CH}_{2} \mathrm{Cl}_{2}: \mathrm{EtOH}: \mathrm{H}_{2} \mathrm{O} \quad(1: 1: 1,1.5: 1: 1$, $2: 1: 1 \mathrm{v} / \mathrm{v})$ and hexane: $\mathrm{CH}_{2} \mathrm{Cl}_{2}:$ EtOH: $\mathrm{H}_{2} \mathrm{O}(1: 0.5: 1: 1$, $1: 1: 1: 1,1: 2: 1: 1 \mathrm{v} / \mathrm{v})$. The test tubes were shaken and the compounds allowed to partition between the two phases. Equal aliquots of each phase were spotted beside each other separately on silica gel TLC plates and developed with the solvent system $\mathrm{CHCl}_{3}$ :ethyl acetate $3: 2$. The results were visualized under UV light and by spraying with vanillin-sulfuric acid (1\%) solution followed by heating. The solvent system was defined as hexane: $\mathrm{CH}_{2} \mathrm{Cl}_{2}: \mathrm{EtOH}: \mathrm{H}_{2} \mathrm{O}(1: 2: 1: 1 \mathrm{v} / \mathrm{v})$.

\section{HSCCC separation procedure}

The solvents of the selected solvent system were thoroughly equilibrated in a separation funnel at room temperature. The upper and lower phases were separated and degassed in an ultrasonic bath for 20 min before use. The sample was prepared by dissolving $400 \mathrm{mg}$ of the chloroform fraction from $S$. cayennesis in $2.5 \mathrm{~mL}$ of each phase of the solvent system and loaded into an injection valve (Rheodyne model 5010 A) equipped with a $5 \mathrm{~mL}$ loop. A P.C Inc countercurrent chromatograph equipped with a multi-layer coil equilibrated by a counterweight was used. The $80 \mathrm{~mL}$ coil was initially filled with the stationary upper phase of the solvent system. Then, rotation started $(850 \mathrm{rpm})$ and the lower mobile phase was pumped into the coil in the head to tail $(\mathrm{H} \rightarrow \mathrm{T})$ direction at a flow rate of 2.0 $\mathrm{mL} / \mathrm{min}$ until hydrodynamic equilibrium was achieved. Under these conditions, the retention of the stationary phase $\left(\mathrm{S}_{\mathrm{F}}\right)$ in the coil was $82.5 \%(V m=14.0 \mathrm{~mL})$. CCC rotation was interrupted in tube 60 and the coil content (organic and aqueous phases) was collected ("washoff"), giving a total of seventy fractions, of $5.0 \mathrm{~mL}$ each. The whole separation experiment was conducted at $27^{\circ} \mathrm{C}$. All fractions obtained by CCC were analyzed by TLC using dichloromethane: acetone: methanol (2:1:0.5) as eluent. The major compound, betulinic acid, was obtained in fractions (FC 38-40) and identified by ${ }^{1} \mathrm{H}$ and ${ }^{13} \mathrm{C}$ NMR spectroscopy and the data compared with those from the literature (Mahato 1994).

\section{Animals and reagents}

Male swiss mice, two month old, were maintained on a $12 \mathrm{~h} \mathrm{light/dark} \mathrm{cycle} \mathrm{(lights} \mathrm{on} \mathrm{at}$ 7 a.m.), with free access to tap water and standard laboratory chow. The experimental protocols using animals were approved by the Committee for Ethics in Animal Research of the Universidade College for Animal Experimentation. The reagents were purchased from Sigma (USA), Amersham Biosciences (USA), Invitrogen (USA) and Merck (Germany) and Molecular Probes (Eugene, OR).

$\mathrm{N}$-acetyl-3,7-dihydroxyphenoxazine (Amplex-Red) and 5-(-6)-chloromethyl-2`,7`-dichlorohydrofluorescein diacetate (CM-H DCFDA) probes were obtained from Sigma-Aldrich, USA. The Mili-Q water was used for preparing the solutions. Fresh rat brain homogenate was 
used as mitochondrial source for oxidative stress assay. The experiments using Amplex Red and CM-H2DCFDA probes with isolated mitochondria were carried out at 37 ${ }^{\circ} \mathrm{C}$. Quercetin was used as antioxidant standard, obtained from Sigma Chemicals and used in all experiments, due to its well-established antioxidant activity. All organic solvents used for High-Speed Countercurrent Chromatography (HSCCC) were of analytical grade and purchased from Tedia Brazil.

\section{Mitochondrial isolation}

Mitochondria from forebrains were isolated as described by Rosenshtraukh et al. (1978) with minor modifications, from two months old swiss mice. Their brains were rapidly removed (within $1 \mathrm{~min}$ ) and put into $10 \mathrm{~mL}$ of ice-cold isolation buffer containing 300 mM mannitol, $1 \mathrm{mM} \mathrm{K}+$-EGTA, $0.1 \%$ bovine serum

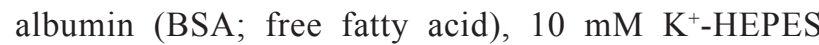
$\mathrm{pH}$ 7.2. The tissues were cut into small pieces using surgical scissors and extensively washed. Then, they were ressuspend in a proportion of $1 / 10(\mathrm{w} / \mathrm{v})$ with the cold isolation buffer, and manually homogenized during two cycles of $10 \mathrm{~s}$ in a Teflon glass potter. The homogenates were centrifuged at $2.000 \mathrm{x} \mathrm{g}$ for $3 \mathrm{~min}$ in a Hitachi Himac SCR20B RPR 20-2 rotor. After centrifugation, the supernatant was centrifuged for 8 min at $12.000 \times \mathrm{g}$. The pellet was suspended in $5 \mathrm{~mL}$ of isolation buffer containing $20 \mu \mathrm{L}$ of $10 \%$ digitonin and centrifuged again for $8 \mathrm{~min}$ at $12.000 \mathrm{x} \mathrm{g}$. The supernatant was discarded and the final pellet gently washed and suspended in cold isolation buffer at an approximate protein concentration of $10 \mathrm{mg} / \mathrm{mL}$. The protein concentration in the samples was determined by the Folin-Lowry method using bovine serum albumin as standard (Lowry et al., 1951). All of the experiments with isolated mitochondria were carried out at 37 ${ }^{\circ} \mathrm{C}$ with continuous stirring in a respiration buffer containing $10 \mathrm{mM}$ Tris- $\mathrm{HCl}, \mathrm{pH} 7.4,0.32 \mathrm{M}$ mannitol, $8 \mathrm{mM}$ inorganic phosphate, $4 \mathrm{mM} \mathrm{MgCl}_{2}, 0.08 \mathrm{mM}$ EDTA, $1 \mathrm{mM}$ EGTA and $0.2 \mathrm{mg} / \mathrm{mL}$ fatty acid-free bovine serum albumin.

Spectrofluorometric measurements of mitochondrial ROS generation

Mitochondrial release of reactive oxygen species (ROS) was assessed by two methods using 10-acetyl-3,7-dihydroxyphenoxazine (Amplex Red) to evaluate $\mathrm{H}_{2} \mathrm{O}_{2}$ or 5-(-6)-chloromethyl-2',7'-

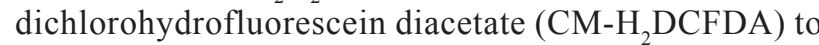
access whole ROS release from mitochondria (Cadenas \& Davies 2000; Cadenas et al., 1977; Chen et al., 2003; Turrens 2003; Turrens \& Boveris 1980; Valeur 2001; Votyakova \& Reynolds 2004). Briefly, for evaluation of $\mathrm{H}_{2} \mathrm{O}_{2}$ release from mitochondria, $0.5 \mathrm{mg}$ protein/ $\mathrm{mL}$ of isolated mitochondria were incubated in the standard respiration buffer supplemented with $1.5 \mu \mathrm{M}$ Amplex Red and 10 units/mL horseradish peroxidase. (HRP). Amplex Red, is a nonfluorescent molecule that when oxidized by hydrogen peroxide in the presence of HRP originates resorufin, a highly fluorescent product. Fluorescence was monitored at excitation and emission wavelengths of $563 \mathrm{~nm}$ and $587 \mathrm{~nm}$, respectively, using a multi-mode microplate reader spectrofluoremeter Spectra Max ${ }^{\circledR}$ M5 (Molecular Devices). For evaluation of whole mitochondrial ROS release, CM-H DCFDA fluorescence, $0.5 \mathrm{mg}$ protein $/ \mathrm{mL}$ of isolated mitochondria were incubated in the standard respiration buffer supplemented with $2 \mu \mathrm{M}$ of CM-H DCFDA. Fluorescence was monitored at excitation and emission wavelengths of $485 \mathrm{~nm}$ and $535 \mathrm{~nm}$, respectively, using a multi-mode microplate reader spectrofluoremeter Spectra Max $^{\circledR}$ M5 (Molecular Devices). The acetate group of CM-H DCFDA is hydrolysed by esterases when it enters the cell and the molecule is trapped inside as the non-fluorescent 5-(-6)-chloromethyl-2`, $7^{`}$ dichlorodihydrofluorescein $\left(\mathrm{CM}-\mathrm{H}_{2} \mathrm{DCFH}\right)$. Oxidation of CM-H $\mathrm{H}_{2} \mathrm{DFH}$ by ROS yields the fluorescent product carboxymethyldichlorofluorescein (CM-DCF), and indirectly measures mitochondrially produced $\mathrm{O}_{2}$ - that has dismutated to $\mathrm{H}_{2} \mathrm{O}_{2}$ through the action of superoxide dismutase. Calibrations were performed by the addition of known quantities of $\mathrm{H}_{2} \mathrm{O}_{2}$. Each experiment was repeated at least three times with different mitochondrial preparations with increasing concentrations $(1-45 \mu \mathrm{M})$ of quercetin (1), verbascoside (2), martinoside (3) and betunilic acid (4) compounds. In all experiments, we detected small changes in the rate of $\mathrm{H}_{2} \mathrm{O}_{2}$ formation among different preparations, but the overall pattern of response to different modulators was not affected. The maximal rate $(100 \%)$ of mitochondrial $\mathrm{H}_{2} \mathrm{O}_{2}$ or $\mathrm{ROS}$ formation was assumed to be the difference between the rate of $\mathrm{H}_{2} \mathrm{O}_{2}$ or ROS formation in the absence or in the presence of succinate.

\section{Statistical analysis}

Statistical analyses were performed using a Tukey's test and ANOVA. Differences were considered statistically significant for $p<0.05$. All results are expressed as means \pm S.E.M. for $n$ independent experiments.

\section{Results and Discussion}

ROS generation rate decrease with increasing concentrations of the natural compounds in mice's brain mitochondria 
The excess of ROS induce lipid peroxidation, especially in brain, since it is inadequately equipped with scavenger antioxidant defense mechanisms and which has easily peroxidizable fatty acid, high content of iron and ascorbate. These features turn brain tissue very vulnerable to free radical and ROS injury (Chen et al., 2003; Halliwell \& Gutteridge, 2002; Halliwell, 2006; Liu, 2002; Sheu et al., 2006). Mitochondria is the most important cellular source of the free radical superoxide anion $\left(\mathrm{O}_{2}{ }^{-}\right)$, which was established as the stoichiometric precursor of mitochondrial $\mathrm{H}_{2} \mathrm{O}_{2}$ (Chen et al., 2003; Sheu et al., 2006; Halliwell \& Gutteridge, 2002).

Little information is available on the levels of natural antioxidant compounds in brain (Halliwell \& Gutteridge, 2002). On the other hand, there is an evidence, based on animal studies, that some phenolics antioxidants compounds (feluric acid and flavonoids such as naringenin and hesperitin) can cross the blood-brain barrier (Halliwell \& Gutteridge, 2002; Sheu et al., 2006, Spencer et al., 2004). Some of the pharmacological properties of medicinal plant like anti-inflammatory property may be linked to their antioxidant potential, antioxidant compounds, which can be due to their ability to scavenge free radicals and ROS, such as $\mathrm{H}_{2} \mathrm{O}_{2}$ and other very reactive non-radical species (Amaral et al., 2009).

In this context we tested the ROS production using two fluorescent probes, Amplex Red (AR) and $\mathrm{CMH}_{2}$ DCDFA, in the experiments using isolated mitochondria from mice's brain, in order to investigate the antioxidant potential of the natural compounds from $S$. cayennensis. The chemiluminescence of CM- $\mathrm{H}_{2}$ DCFDA and Amplex Red (AR) catalyzed by horseradish peroxidase (HRP) enzymatic coupled assays have been employed in several in vitro studies for the quantification of low concentrations of ROS and $\mathrm{H}_{2} \mathrm{O}_{2}$ (Chen et al., 2003; Sheu et al., 2006; Valeur, 2001). The addition of $\mathrm{H}_{2} \mathrm{O}_{2}$ to a sample consisting of $\mathrm{AR}$ and HRP. HRP in $\mathrm{pH} 7.4$, buffer immediately generated a strong absorption band with maximum at $587 \mathrm{~nm}$, indicating conversion of AR to resorufin. Increasing $\mathrm{H}_{2} \mathrm{O}_{2}$ produced more resorufin, the concentration of which was proportional to the concentrated $\mathrm{H}_{2} \mathrm{O}_{2}$ used (Chen et al., 2003; Sheu et al., 2006). The acetate group of $\mathrm{CM}-\mathrm{H}_{2} \mathrm{DCFDA}$ is hydrolysed by esterases when it enters the cell and the molecule is trapped inside as the non-fluorescent $\mathrm{CM}-\mathrm{H}_{2} \mathrm{DCFH}$. CM$\mathrm{H}_{2} \mathrm{DCFH}$ was chosen because, unlike underivatized dichlorodihydrofluorescein, it is well retained in cells and, in this case, in the mitochondrial matrix (Valeur, 2001; Votyakova \& Reynolds, 2004).

The verbascoside (2), martinoside (3) and betulinic acid (4) resulting from the roots of ethanol extract of S.cayennensis has been previously assayed by our group for antioxidant activities (DPPH freeradical assay and Saccharomyces cerevisiae cells, an eukaryotic cell model) (De Souza et al., 2010). All compounds afforded the best results in the two assays and were therefore, chosen for this study. The remarkable capacity of these natural compounds to function in vitro as antioxidants has been demonstrated in this study.
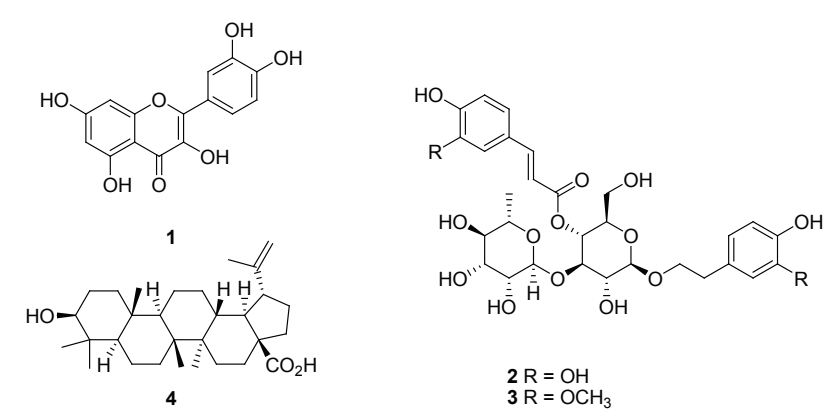

We induced the isolated mitochondria to produce ROS using the mitochondrial substrate succinate and the mitochondrial complex III inhibitor antimycin A. Each experiment was repeated at least three times with different mitochondrial preparations. The compounds verbascoside and martinoside presented the best antioxidant effects, according to their IC50 for ROS scavenger (Table 1). Table 2 and Table 3 show representative experiments. The differences between the antioxidant efficacy of verbascoside, martinoside and betunillic acid comparing to quercetin became clear in the concentration range of 1 to $20 \mu \mathrm{M}$ (Table 2) and of 1 to $10 \mu \mathrm{M}$ (Table 3).

Table 1. Effect of different compounds with antioxidant activities.

\begin{tabular}{|c|c|c|}
\hline \multicolumn{3}{|c|}{ IC50 (uM) values for ROS scavenger } \\
\hline Compounds & $\begin{array}{c}\mathrm{H}_{2} \mathrm{O}_{2}(\text { Amplex red }) \\
\text { IC50 }\end{array}$ & $\begin{array}{c}\text { ROS } \\
\left(\mathrm{CMH}_{2} \mathrm{DCFDA}\right) \mathrm{IC} 50\end{array}$ \\
\hline Betunilic acid & 28.11 & 2.07 \\
\hline Martinoside & 19.34 & 0.54 \\
\hline Quercetin & - & 7.27 \\
\hline Verbascoside & 5.25 & 0.54 \\
\hline
\end{tabular}

Table 1 shows for the Amplex red probe, after the titulation curve with $\mathrm{H}_{2} \mathrm{O}_{2}$, with the $\mathrm{IC}_{50}$ (inhibitory concentration, 50\%) of 19,000 pmol of $\mathrm{H}_{2} \mathrm{O}_{2}$ consumed by each compound. For the $\mathrm{CMH}_{2}$ DCFDA probe, the IC50 was 29,325 pmol of $\mathrm{H}_{2} \mathrm{O}_{2}$ consumed by each compound.

On the other hand, the current study demonstrates that AR (Table 3) is more sensitive probe than $\mathrm{CMH}_{2}$ DCFDA (Table 2) when the assay is conducted at $\mathrm{pH}$ 7.4. Perhaps, the hydrolysis of CM- $\mathrm{H}_{2} \mathrm{DCFDA}$ in buffer at physiological temperature and $\mathrm{pH}$ is not rapid, it must be taken into consideration in experiments lasting longer than 
several minutes, and where buffer capacity is low and $\mathrm{pH}$ is variable. In addition, the oxidized product of Amplex Red has excitation and emission maxima at 563 and 587 $\mathrm{nm}$, in comparison with those of $\mathrm{CMH}_{2}$ DCFDA at 485 and $535 \mathrm{~nm}$. These superior spectral properties maybe are important for avoiding interference from autofluorescence in assays involving biological samples. Finally, there are a few factors affecting the sensitivity of resorufin for detecting $\mathrm{H}_{2} \mathrm{O}_{2}$ (Valeur, 2001).

The number of phenolic hydroxyl groups may play an important role in their scavenging activity (Justino et al., 2004; Van Acker et al., 1993). The literature reports that compounds with hydroxyl in the ortho-aromatic position, like quercetin, have more antioxidant activity against ROS (Justino et al., 2004; Soobratte et al., 2005). In the presence of $\mathrm{H}_{2} \mathrm{O}_{2}$, for example, phenolic compounds such as ortho-quinol suffer a reduction reaction generating ortho-quinones and water as products (Dewick, 2002; Justino et al., 2004; Soobratte et al., 2005; Van Acker et al., 1993). The verbascoside (2) and the flavonoid quercetin (1) have four hydroxyls in their structures capable of suffering oxidation reactions in the presence of peroxides, such as $\mathrm{H}_{2} \mathrm{O}_{2}$ (Dewick, 2002; Zhou \& Sadik, 2008).

Table 3 shows the antioxidant activity of the tested compounds in $\mathrm{H}_{2} \mathrm{O}_{2}$. Again, the verbascoside presented the better antioxidant capacity among the compounds tested with about $10 \mu \mathrm{M}$ of concentration. Both betulinic acid (4) and martinoside (3) showed similar antioxidant effect around the concentration of $10 \mu \mathrm{M}$ (Table 3). A possible explanation for this would be that the carboxylic acid group presents a greater oxidation potencial comparing to the phenolic compound (Dewick, 2002; Justino et al., 2004). This property could give to betulinic acid a similar antioxidant capacity when compared with martinoside, which has only a phenolic hydroxyl group on each of its two aromatic rings. Surprisingly, both verbascoside and martinoside showed more antioxidant activity than quercetin that was used as standard, due to its wellestablished antioxidant activity (Table 1 and 3) (Belinha et al., 2007; Ho et al., 2004; Santos et al., 2008; Oken et al., 1998; Soobrattee et al., 2005; Spencer et al., 2004; Zhou \& Sadik, 2008).

Nevertheless, only verbascoside has four hydroxyls on ortho position, in its two aromatic rings. This structural information could justify its high antioxidant activity when compared to the other compounds tested (Zhou \& Sadik, 2008). Perhaps, the weak antioxidant activity of quercetin reported here may be related to the solubility and ability of quercetin to be distributed to a less or greater extent of its diffusion speed, between the lipid-water interface, or the distribution in the hydrophobic core of the mitochondrial membrane (Justino et al., 2004; Oliveira \& Kowaltowski, 2004; Pulido et al., 2005; Spencer et al., 2004).

In summary, present results show that verbascoside, martinoside and betulinic acid are useful antioxidants for preventing oxidative stress-related mitochondrial dysfunction, and as such may find use in the management of a range of acute and chronic disease processes. However, very little is known about the

Table 2. ROS generation rate using the fluorescent probe $\mathrm{CM}-\mathrm{H}_{2} \mathrm{DCFDA}$, during state 2 respiration induced by $10 \mathrm{mM}$ succinate (suc), with increasing compounds concentrations (1-45 $\mu \mathrm{M})$ of verbascoside, quercetin, betunilic acid and martinoside.

\begin{tabular}{lcccccc}
\hline \multicolumn{7}{c}{ Relative rate of mitochondrial ROS generation $(\mathrm{Vo} / \mathrm{Vi})$} \\
\hline Compounds & Control & $1(\mu \mathrm{M})$ & $10(\mu \mathrm{M})$ & $20(\mu \mathrm{M})$ & $30(\mu \mathrm{M})$ & $45(\mu \mathrm{M})$ \\
\hline Verbascoside & $0,0500 \pm 0,00666$ & $0,0290 \pm 0,00120^{\mathrm{a}}$ & $0,0270 \pm 0,00145^{\mathrm{a}}$ & $0,0220 \pm 0,00361^{\mathrm{a}}$ & $0,0150 \pm 0,00267^{\mathrm{a}}$ & $0,0140 \pm 0,00451^{\mathrm{a}}$ \\
Martinoside & $0,0440 \pm 0,01049$ & $0,0130 \pm 0,00033^{\mathrm{a}}$ & $0,0120 \pm 0,00115^{\mathrm{a}}$ & $0,0070 \pm 0,00033^{\mathrm{a}}$ & $0,0050 \pm 0,00088^{\mathrm{a}}$ & $0,0050 \pm 0,00120^{\mathrm{a}}$ \\
Quercetin & $0,0540 \pm 0,01357$ & $0,0130 \pm 0,00033^{\mathrm{a}}$ & $0,0100 \pm 0,00033^{\mathrm{a}}$ & $0,0070 \pm 0,00066^{\mathrm{a}}$ & $0,0050 \pm 0,00120^{\mathrm{a}}$ & $0,0040 \pm 0,00088^{\mathrm{a}}$ \\
Betulinic acid & $0,0600 \pm 0,00549$ & $0,0300 \pm 0,00524^{\mathrm{a}}$ & $0,0240 \pm 0,00260^{\mathrm{a}}$ & $0,0210 \pm 0,00291^{\mathrm{a}}$ & $0,0160 \pm 0,00265^{\mathrm{a}}$ & $0,0120 \pm 0,00176^{\mathrm{a}}$ \\
\hline
\end{tabular}

${ }^{\mathrm{a}} p<0.05$ relative to $1,10,20,30$ and $45 \mu \mathrm{M}$. The values are mean $\pm \mathrm{SE}$ from at least three independent mitochondrial preparations for each assay conditiona: control vs $1,10,20,30,45$.

Table 3. $\mathrm{ROS}\left(\mathrm{H}_{2} \mathrm{O}_{2}\right)$ generation rate using the fluorescent probe Amplex Red, during state 2 respiration induced by $10 \mathrm{mM}$ succinate (suc), with increasing compounds concentrations (1-45 $\mu \mathrm{M})$ of verbascoside, quercetin, betunilic acid, and martinoside.

\begin{tabular}{lcccccc}
\hline \multicolumn{5}{c}{ Relative rate of mitochondrial ROS generation $(\mathrm{Vo} / \mathrm{Vi})$} \\
\hline Compounds & Control & $1(\mu \mathrm{M})$ & $10(\mu \mathrm{M})$ & $20(\mu \mathrm{M})$ & $30(\mu \mathrm{M})$ & $45(\mu \mathrm{M})$ \\
\hline Verbascoside & $6,911 \pm 0,08170$ & $1,363 \pm 0,06059^{\mathrm{a}}$ & $0,4367 \pm 0,01618^{\mathrm{a}, \mathrm{b}}$ & $0,2557 \pm 0,04156^{\mathrm{a}, \mathrm{b}}$ & $0,2800 \pm 0,05029^{\mathrm{a}, \mathrm{b}}$ & $0,2833 \pm 0,06164^{\mathrm{a}, \mathrm{b}}$ \\
Martinoside & $6,651 \pm 0,09650$ & $1,381 \pm 0,06351^{\mathrm{a}}$ & $1,015 \pm 0,06784^{\mathrm{a}, \mathrm{b}}$ & $0,6773 \pm 0,07518^{\mathrm{a}, \mathrm{b}}$ & $0,6100 \pm 0,08685^{\mathrm{a}, \mathrm{b}, \mathrm{c}}$ & $0,5267 \pm 0,08225^{\mathrm{a}, \mathrm{b}, \mathrm{c}}$ \\
Quercetin & $6,943 \pm 0,10513$ & $1,362 \pm 0,6529^{\mathrm{a}}$ & $1,477 \pm 0,3324^{\mathrm{a}}$ & $1,107 \pm 0,2052^{\mathrm{a}}$ & $0,7627 \pm 0,1621$ & $0,8267 \pm 0,1470^{\mathrm{a}}$ \\
Betulinic acid & $6,873 \pm 0,06754$ & $1,428 \pm 0,1159^{\mathrm{a}}$ & $1,053 \pm 0,1195^{\mathrm{a}}$ & $0,9297 \pm 0,09556^{\mathrm{a}, \mathrm{b}}$ & $0,6543 \pm 0,07911^{\mathrm{a}, \mathrm{b}}$ & $0,5670 \pm 0,07365^{\mathrm{a}, \mathrm{b}, \mathrm{c}}$ \\
\hline
\end{tabular}

${ }^{\mathrm{a}} p<0.05$ relative to control, ${ }^{\mathrm{b}} p<0.05$ relative to $1 \mu \mathrm{M},{ }^{\mathrm{c}} p<0.05$ relative to $10 \mu \mathrm{M}$. The values are mean \pm SE from at least 3 independent mitochondria preparations for each assay condition. a: control vs $1,10,20,30,45$; b: 1 vs $10,20,30,45$; c: 10 vs 20,30,45. 
effects of natural compounds isolated from plants in the cellular metabolism of humans, especially after cross the blood-brain barrier and interaction with brain cells (Justino et al., 2004; Spencer et al., 2004). Preclinical studies in vivo models are needed to evaluate the effectiveness and toxicity of mitochondrially targeted antioxidants before recommending specific doses for human treatment.

\section{Acknowledgments}

This research was supported by grants from CAPES and CNPq, Brazil. We thank Dr. Inês $M$. Oliveira (UFRRJ) for her help in identifying the voucher specimen.

\section{References}

Amaral S, Mira L, Nogueira JMF, da Silva AP, Florencio MH 2009. Plant extracts with anti-inflammatory properties - a new approach for characterization of their bioactive compounds and establishment of structure-antioxidant activity relationships. Bioorg Med Chemi 17: 1876-1883.

Belinha I, Amorim MA, Rodrigues P, De Freitas V, MoradasFerreira P, Mateus N, Costa V 2007. Quercetin increases oxidative stress resistance and longevity in S. cerevisiae. J Agric Food Chem 55: 2446-2451.

Boveris A, Cadenas E, Stoppani AO 1976. Role of ubiquinone in the mitochondrial generation of hydrogen peroxide. Biochem J 156: 435e444.

Boveris A, Chance B 1973. The mitochondrial generation of hydrogen peroxide: general properties and effect of hyperbaric oxygen. Biochem J 134: 707-716.

Brand DM, Affourtit CE, Green K, Lambert JA, Miwa S, Pakay LJ, Parker N 2004. Serial Review: The powerhouse takes control of the cell: the role of mitochondria in signal transduction. Free Rad Biol Med 37: 755-767.

Cadenas E, Boveris A, Ragan CI, Stopani AO 1977. Production of superoxide radicals and hydrogen peroxide by NADH-ubiquinone reductase and ubiquinol-cytochrome c reductase from beef-heart mitochondria. Arch Biochem Biophys 180: 248-257.

Cadenas E, Davies KJ 2000. Mitochondrial free radical generation, oxidative stress, and aging. Free Radic Biol Med 29: 222-230.

Chen Q, Vazquez EJ, Moghaddas S, Hoppel CL, Lesnefsky EJ 2003. Production of reactive oxygen species by mitochondria: central role of complex III. J Biol Chem 278: 36027-36031.

De Souza PA 2004. Estudo fitoquímico e farmacológico P. bahienenis e $\mathrm{S}$.cayennensis. Rio de Janeiro, 139p. Dissertação de Mestrado, Programa de Pós-graduação em Química Orgânica, Universidade Federal Rural do Rio de Janeiro.
De Souza PA, Silva CG, Machado BRP, Lucas NC, Leitão GG, Eleutherio ECA, Dellamora Ortiz GM, Benchetrit LC 2010. Evaluation of antimicrobial, antioxidant and phototoxic activities of extracts and isolated compounds from Stachytarpheta cayennesis (Rich.) Vahl. Rev Bras Farmacogn 20: 922-928.

Dewick PM 2002. Medicinal Natural Products. A Biosynthetic Approach. $2^{\text {nd }}$ ed.John Wiley \& Sons Ltd. England.

Freitas RM, Vasconcelos SMM, Souza FCF, Viana GSB, Fonteles MMF 2005. Oxidative stress in the hippocampus after pilocarpine-induced status epilepticus in Wistar rats. FEBS J 272: 1307-1312.

Halliwell B 2006. Oxidative stress and neurodegeneration? Where are we now. J Neurochem 97: 1634-1658.

Halliwell B, Gutteridge JMC 2002. Free Radicals in Biology and Medicine. Oxford University Press.

Ho J, Heo HJ, Lee CY 2004. Protective effects of quercetin and vitamin $\mathrm{C}$ against oxidative stress-induced neurodegeneration. J Agric Food Chem 52: 7514751.

Huang D, Boxin O, Prior LR 2005. The chemistry behind antioxidant capacity assays. J Agric Food Chem 53: 1841-185.

Justino CG, Santosa MR, Canarioa S, Borgesa C, Florencio MH, Miraa L 2004. Plasma quercetin metabolites: structure-antioxidant activity relationships. Arch Biochem Biophys 432: 109-121.

Leitão GG, De Souza PA, BrowL, Moraes AA 2005. Stepgradient CCC separation of phenylpropanoid and iridoid glycosides from roots of Stachytarpheta cayennesis (Rich.) Vahl. J Liq Chromatogr Relat Technol 28: 2053-2060.

Liu Y 2002. Generation of reactive oxygen species by the mitochondrial electron transport chain. $J$ Neurochem 80: 780-787.

Lowry OH, Rosebrough NJ, Farr AL, Randall RJ 1951. Protein measurement with the Folin phenol reagent. $J$ Biol Chem 193: 265-275.

Mahato BS 1994. ${ }^{13} \mathrm{C}$ NMR Spectra of pentacyclic triterpenoids - a compilation and some salient features. Phytochemistry 37: 1517-1575.

Oken BS, Storzbach DM, Kaye JA 1998. The efficacy of Ginkgo biloba on cognitive function in Alzheimer disease. Archiv Neurol 55: 1409-1415.

Oliveira GA, Kowaltowski AJ 2004. Phosphate increases mitochondrial reactive oxygen species release. Free Radic Res 38: 1113-1118.

Penido C, Costa KA, Futuro DO, Paiva SR, Kaplan MAC, Figueiredo MR, Henriques MGMO 2006. Antiinflammatory and anti-ulcerogenic properties of Stachytarpheta cayennensis (L.C. Rich) Vahl. J Ethnopharmacol 104: 225-233.

Pulido RJ, Orensanz A, Saura-Calixto L 2005. Study of plasma antioxidant status in Alzheimer's disease. Eur J Neurol 12: 531-535. 
Roginsky VA, Barsukova TK, Remorova AA 1996. Moderate antioxidative efficiencies of flavonoids during peroxidation of methyl linoleate in homogenous and micellar solutions. J Am Oil Chem Soc 73: 777-786.

Rosenshtraukh LV, Saks VA, Undrovinas AI, Chazov EI, Smirnov VN, Sharov VG 1978. Studies of energy transport in heart cells. The effect of creatine phosphate on the frog ventricular contractile force and action potential duration. Biochem Med 19: 148-164.

Santos MR, Rodriguez-Gomez MJ, Justino GC, Charro N, Florencio MH, Mira L 2008. Influence of the metabolic profile on the in vivo antioxidant activity of quercetin under a low dosage oral regimen in rats. $\mathrm{Br}$ J Pharmacol 153: 1750-1761.

Schapira AH 2006. Etiology of Parkinson's disease. Neurology 66: $\mathrm{S} 10-\mathrm{S} 23$

Schapoval EES, Winter de Vargas MR, Chaves CG, Bridi R, Zuanazzi JA, Henriques AT 1998. Antiinflammatory and antinociceptive activities of extracts and isolated compounds from Stachytarpheta cayennensis. J Ethnopharmacol 60: 53-59.

Sheu SS, Nauduri D, Anders MW 2006. Targeting antioxidants to mitochondria: A new therapeutic direction. Biochim Biophys Acta 1762: 256 -265.

Soobrattee MA, Neergheen VS, Luximon-Ramma A, Aruoma OI, Bahorun T 2005. Phenolics as potential antioxidant therapeutic agents: Mechanism and actions. Mutat Res 579: 200-213.

Spencer JPE, El Mohsen MMA, Rice-Evans C 2004. Cellular uptake and metabolism of flavonoids and their metabolites: implications for their bioactivity. Arch Biochem Biophys 423: 148-161.

Tomé AR, Feng D, Freitas RM 2010a.The effects of alphatocopherol on hippocampal oxidative stress prior to in pilocarpine-induced seizures. Neurochem Res 35: 580-587.

Tomé AR, Ferreira PMP, Freitas RM 2010b. Inhibitory action of antioxidants (ascorbic acid or $\alpha$-tocopherol) on seizures and brain damage induced by pilocarpine in rats. Arq Neuropsiquiatr 68: 355-361.

Turrens JF 2003. Mitochondrial formation of reactive oxygen species. J Physiol 552: 335-344.

Turrens JF, Boveris A 1980. Generation of superoxide anion by the NADH dehydrogenase of bovine heart mitochondria. Biochem J 191: 421-427.

Valeur B 2001. Molecular Fluorescence: Principles and Applications. Wiley-VCH Verlag GmbH Press.

Van Acker SA, Koymans LM, Bast A 1993. Molecular pharmacology of vitamin E: structural aspects of antioxidant activity. Free Rad Biol Med 15: 311-328.

Votyakova TV, Reynolds IJ 2004. Detection of hydrogen peroxide with Amplex Red: interference by NADH and reduced glutathione auto-oxidation. Arch Biochem Biophys 431: 138-44.

Xavier SM, Barbosa CO, Barros DO, Silva RF, Oliveira AA, Freitas RM 2007. Vitamin C antioxidant effects in hippocampus of adult Wistar rats after seizures and status epilepticus induced by pilocarpine. Neurosci Lett 1: 76-79.

Zhou A, Sadik AO 2008. Comparative analysis of quercetin oxidation by electrochemical, enzymatic, autoxidation, and free radical generation techniques: A mechanistic study. J Agric Food Chem 56: 12081-12091.

Zhou M, Diwu Z, Panchuk-Voloshina N, Haugland RP 1997. A stable nonfluorescent derivative of resorufin for the fluorometric determination of trace hydrogen peroxide: applications in detecting the activity of phagocyte NADPH oxidase and other axidases. Anal Biochem 253: 162-168.

\section{*Correspondence}

Pierre André de Souza

Instituto de Química, Departamento de Química Orgânica, Laboratório de Fotoquímica

Universidade Federal do Rio de Janeiro, 21949-900 Rio de Janeiro-RJ, Brazil

pierreandre@iq.ufrj.br 